\title{
Choroidal Changes in Diabetic Patients With Different Stages of Diabetic Retinopathy
}

Tariq Hamadneh ${ }^{1,2}$, Saba Aftab 3, ${ }^{\text {, Nazleen Sherali }}{ }^{5,4}$, Rishwanth Vetrivel Suresh ${ }^{4}$, Nicholas Tsouklidis 6, 4, 7 , MeiXia An ${ }^{1}$

1. Ophthalmology, The Third Affiliated Hospital of Southern Medical University, Guangzhou, CHN 2. Ophthalmology, California Institute of Behavioral Neurosciences \& Psychology, Fairfield, USA 3. Medicine, Hamdard College of Medicine and Dentistry, Karachi, PAK 4. Medicine, California Institute of Behavioral Neurosciences \& Psychology, Fairfield, USA 5. Medicine, Liaquat University of Medical and Health Sciences, Jamshoro, PAK 6. Health Care Administration, University of Cincinnati Health, Cincinnati, USA 7. Medicine, Atlantic University School of Medicine, Gros Islet, LCA

Corresponding author: MeiXia An, anmeixia@163.com

\begin{abstract}
Diabetic retinopathy (DR) is one of the long-term microvascular complications of diabetes mellitus (DM) and is considered a leading cause of vision loss worldwide. Chronic hyperglycemia can cause microvascular abnormalities to the retina and the choroid as well. The vascular tissue of the choroid supplies blood to the outer retina, photoreceptors, and retinal pigment epithelium. It plays an important role in the metabolic exchange of the retina. Many experimental studies reported that choroidal pathology in diabetic patients might play a role in developing DR. Choroidal thickness (CT) can reflect changes in the vasculature of the choroid and can be used to assess the vascularity of the choroid itself. CT differs between healthy and diseased states of the eye as well as with the aging process. This means that thinner or thicker choroid may indicate an ocular disease. Choroidal vascularity index (CVI) is also used as a marker for choroidal vascularity assessment and indirectly measures choroidal vascularity quantitatively. Many studies have been conducted to evaluate the choroid in many different ocular diseases. However, the results regarding CT in DM, especially in patients with DR, are various as thickened, thinned, or no changes. Thus, the status of the choroid in patients with DM with or without DR remains controversial between researchers. In this systematic review, we reviewed 18 articles that were done to investigate the relationship between structural choroidal changes in diabetic patients with different stages of DR, focusing on CT, CVI, and some other parameters evaluating choroidal changes.
\end{abstract}

Categories: Ophthalmology

Keywords: choroids, sattler's layer, haller's layer, choriocapillaris, diabetic retinopathies, diabetic, retinopathy, choroidal thickness, choroidal vascularity index, cvi

Received 09/18/2020 Review began 09/27/2020 Review ended 09/30/2020 Published 10/09/2020

\section{(c) Copyright 2020}

Hamadneh et al. This is an open access article distributed under the terms of the Creative Commons Attribution License CC-BY 4.0., which permits unrestricted use, distribution, and reproduction in any medium, provided the original author and source are credited.

\section{Introduction And Background}

Diabetes mellitus (DM) is classified into type one diabetes mellitus, formerly known as insulin-dependent diabetes mellitus (IDDM), and type two diabetes mellitus, formerly known as non-insulin-dependent diabetes mellitus (NIDDM). Type one DM usually results from the destruction of pancreatic $\beta$-cells, leading to absolute insulin deficiency. Type two diabetes mellitus is characterized by insulin resistance that may or may not be accompanied by insulin deficiency. There are also other forms of DM, such as genetically mediated form secondary to endocrinopathy, drug- or chemical-induced DM [1].

Diabetic retinopathy (DR) is one of the long-term microvascular complications of DM and is believed to be a leading cause of vision loss worldwide among patients aged 25-74 years, especially in developed countries such as the United States. DR is classified clinically according to the severity of the disease into stages. In non-proliferative diabetic retinopathy (NPDR), there are changes in the intraretinal vasculature, but without newly formed extraretinal fibrovascular tissue. NPDR is also classified into mild, moderate, and severe forms according to severity. Proliferative diabetic retinopathy (PDR) is the most advanced stage of DR, which usually results after progression through the sequential stages of NPDR. PDR is characterized by the neovascularization of the retina due to chronic ischemia induced by DM. PDR is classified clinically into either early PDR or PDR with high-risk characteristics. Diabetic macular edema (DME) is characterized by swelling of the central retina. It is mainly caused by retinal vascular hyperpermeability, which can be developed in any stage of DR. DME is classified as a center-involved and non-center involved DME based on retinal subfield thickening of optical coherence tomography (OCT) [1].

The prevalence of DM is increasing globally due to the increased life expectancy and the improvement in controlling blood sugar levels. It is expected that DM will affect 642 million individuals by 2040, leading to an increased prevalence of DR as well. One-third of the global diabetic patients are estimated to have DR, and one-third of DR patients are estimated to have sight-threatening DR. There is a direct association between the duration of DM and the prevalence of DR [1]. 
The chronic hyperglycemia in diabetic patients results in biochemical and molecular pathway changes such as increases in inflammatory oxidative stress, advanced glycation end products, and protein kinase C pathways that ultimately cause endothelial damage and pericyte loss, which can explain the pathogenesis of DR in these patients. Over time, basement membrane thickening and selective loss of pericytes in retinal capillaries cause occlusion of these capillaries leading to decreased retinal perfusion, which ultimately leads to retinal neovascularization that develops in response to increased intraocular vascular endothelial growth factor (VEGF) secretion produced by ischemic retinal tissue. Moreover, endothelial damage can lead to the development of retinal edema due to serum leakage [1]. The chronic hyperglycemia can cause microvascular abnormalities to the choroid as well. The choroid is a vascular layer with pigmented stroma between the retina and the sclera. The choroid is supplied by the posterior ciliary arteries. The outer layer of the choroid, known as the Haller layer, contains large caliber vessels. These vessels divide into smaller caliber vessels in a layer known as the Sattler layer [1].

The vascular tissue of the choroid supplies blood to the outer retina, photoreceptors, and retinal pigment epithelium. It plays an important role in the metabolic exchange of the avascular fovea [2]. Numerous experimental studies have reported that choroidal pathology in diabetic patients may play a role in developing DR [3,4]. It was noticed that some pathological changes in the vessels of the choroid are similar to those observed in retinal vessels of DR patients [3]. The thickness of the choroid is maximum posteriorly and becomes thinner more anteriorly. The thickness of the choroid in the central macular area and at the ora serrata is $0.22 \mathrm{~mm}$ and $0.1 \mathrm{~mm}$, respectively. In healthy volunteers with a mean age of 50 , subfoveal choroidal thickness (SFCT) measured by spectral-domain optical coherence tomography (SD-OCT) is 287 $\mu \mathrm{m}$. The thickness of the choroid differs between healthy and diseased states of the eye as well as with the aging process. This means that thinner or thicker choroid may indicate an underlying eye disease [1]. Choroidal thickness (CT) reflects changes in the choroidal vasculature, and this can be used to evaluate choroidal vascular abnormalities and its association with ocular diseases. Many studies have used CT as an indicator of choroidal and retinal blood flow [5-8]. However, there are many factors that may affect CT requiring more investigation about its effectiveness as a marker for the assessment of choroidal and retinal vascular structural characteristics.

With the recent improvement in imaging techniques, the choroid is studied and evaluated by indocyanine green angiography (ICGA) and laser doppler flowmetry $[4,9,10]$. More recently, the choroid is better evaluated by the enhanced depth imaging-optical coherence tomography (EDI-OCT), which can obtain cross-sectional images with high quality and resolution [11]. EDI-SD-OCT can measure CT and changes in choroidal vessels in several chorioretinal diseases [11]. Recent advances in swept-source-optical coherence tomography (SS-OCT) systems, which utilize longer wavelengths and faster scanning speeds, have helped us better visualize the choroidal vasculature, even microvascular changes due to improved tissue penetration and spatial resolution [12].

Agrawal et al. proposed the choroidal vascularity index (CVI) as a marker to assess vascular structure using EDI-OCT [13]. Using OCT, the total choroidal area (TCA), the stromal area (SA), and vascular luminal area (LA) can be measured. CVI, which is defined as the proportion of LA to TCA, is considered a more robust marker for choroidal vascularity assessment and indirectly measures choroidal vascularity quantitatively, which enables us to overcome the limitation of using CT alone and makes it less affected by physiological factors [14]. Many studies have been conducted to evaluate the choroid in many different eye diseases. However, the results regarding CT in DM, especially in patients with DR, were various as thickened, thinned, or no changes. Thus, the status of the choroid in patients with DM, with or without DR, remains controversial and needs further investigations.

This systematic review aims to review the recent literature of choroidal structural changes in diabetic patients and to see if there is a relationship between these choroidal structural changes and the severity of DR. We also want to review the different measurement variables used to assess changes in the choroid structures and how these measurement variables can help in the diagnosis, prognosis, and possible implication in the management of diabetic patients with or without DR.

\section{Review}

\section{Method}

PubMed database was exclusively and systematically accredited for the collection of corresponding data. The first search based on using keywords, medical subject headings (MeSH) terms and MeSH subheadings, yielded 252 results. After applying inclusion and exclusion criteria (free full text, last 10 years, English language), 44 scientific articles were found. After reviewing the articles and eliminating abstract reviews and less relevant articles not specifying the outcome of interest, 18 scientific papers were included in our final review. All 18 articles met the quality specification and were peer-reviewed.

\section{Inclusion and exclusion criteria}

All selected scientific papers were written in English and included data collected and reviewed from the last 10 years. Free full-text papers were exclusively reviewed. Many studies measured more than one parameter 
in patients with diabetes mellitus and DR. Papers investigating the parameters and markers related to the choroid structure were included, mainly CT and CVI. Papers excluded were not investigating changes of the choroid itself.

\section{Results}

Table 1 contains some general information about the studies reviewed in this article. Endo et al., Wang and Tao, Gupta et al., Rewbury et al., Ohara et al., Tan et al., Hua et al., Kim et al., Sudhalkar et al., Totan et al., Gerendas et al., Lee et al., Adhi et al., Regatieri et al., and Gołębiewska et al. evaluated CT measurements and some of these studies also evaluated CVI in diabetic patients with and without DR as described in Table 2 [14-28]. Kim et al. only investigated for CVI in these patients [29]. Dodo et al. and Nesper et al. used choroidal parameters other than CT and CVI to evaluate choroidal changes [30,31].

\begin{tabular}{|c|c|c|c|c|}
\hline Study & Location & $\begin{array}{l}\text { Study } \\
\text { Period }\end{array}$ & Samples & Method \\
\hline $\begin{array}{l}\text { Endo et al. } \\
\text { [15] }\end{array}$ & Japan & $\begin{array}{l}\text { December } \\
2013-\text { April } \\
2018\end{array}$ & $\begin{array}{l}318 \text { eyes of } 159 \mathrm{DM} \text { patients and age-matched } 100 \text { eyes of } 79 \text { healthy controls. Cases } \\
\text { have no ocular treatment history. }\end{array}$ & EDI-OCT \\
\hline $\begin{array}{l}\text { Wang and } \\
\text { Tao }[16]\end{array}$ & China & 2019 & $\begin{array}{l}104 \text { eyes, divided into four groups: healthy controls }(n=38) \text {, DM without DR eyes }(n=22) \text {, } \\
\text { PRP-untreated NPDR eyes ( } n=24) \text {, PRP-untreated PDR eyes }(n=20) \text {. }\end{array}$ & EDI-OCT \\
\hline $\begin{array}{l}\text { Gupta et al. } \\
\text { [17] }\end{array}$ & $\begin{array}{l}\text { South } \\
\text { India }\end{array}$ & $\begin{array}{l}\text { September } \\
1,2015- \\
\text { December } \\
31,2016\end{array}$ & $\begin{array}{l}82 \text { eyes of } 52 \text { patients with treatment-naive DME with varying grades of DR and } 86 \text { eyes of } \\
43 \text { healthy control patients. }\end{array}$ & EDI-OCT \\
\hline $\begin{array}{l}\text { Rewbury et } \\
\text { al. [18] }\end{array}$ & $\begin{array}{l}\text { Oxford, } \\
\text { UK }\end{array}$ & $\begin{array}{l}\text { January } \\
\text { 2012- } \\
\text { February } \\
2013\end{array}$ & $\begin{array}{l}145 \text { eyes from } 95 \text { patients with untreated type two DM and moderate-to-severe visual loss } \\
\text { were included. Eyes were divided into two groups based on the presence or absence of } \\
\text { foveal involving DME and classified according to retinopathy grade: R1 (mild NPDR) } \\
\text { ( } n=87), R 2 \text { (msNPDR) ( } n=37) \text {, and R3 (PDR) ( } n=21) \text {. }\end{array}$ & EDI-OCT \\
\hline $\begin{array}{l}\text { Ohara et al. } \\
\text { [19] }\end{array}$ & Japan & $\begin{array}{l}\text { August } \\
\text { 2014- } \\
\text { March } \\
2015\end{array}$ & $\begin{array}{l}\text { Healthy subjects ( } n=20) \text {, diabetic patients without DR }(n=14), m m N P D R(n=16) \text {, severe } \\
\text { NPDR ( } n=11) \text { and PDR without PRP ( } n=18) \text { [total is } 79 \text { people] were enrolled. For eyes with } \\
\text { DR, only treatment-naive eyes were included. } 32 \text { eyes [ } 19 \text { eyes with PDR and } 13 \text { eyes with } \\
\text { severe NPDR] for which PRP was necessary were also analyzed. }\end{array}$ & SS-OCT \\
\hline $\begin{array}{l}\text { Tan et al. } \\
\text { [20] }\end{array}$ & Singapore & 2015 & $\begin{array}{l}38 \text { eyes of } 19 \text { age and gender-matched healthy controls and } 38 \text { eyes of } 19 \text { patients with } \\
\text { DM were analyzed. }\end{array}$ & EDI-OCT \\
\hline $\begin{array}{l}\text { Hua et al. } \\
\text { [21] }\end{array}$ & China & 2013 & $\begin{array}{l}\text { The study included } 80 \text { eyes from } 40 \text { patients. Group one consisted of } 62 \text { eyes from } 31 \text { DR } \\
\text { cases, which were qualitatively assessed. This group included } 13 \text { eyes with mild NPDR, } 11 \\
\text { with moderate NPDR, } 15 \text { with severe NPDR, and } 23 \text { with PDR. Group two consisted of } 18 \\
\text { DME eyes from nine NPDR cases, which were quantitatively assessed for choroids. In } \\
\text { each case, one eye had SMD and was placed in the SMD subgroup while the other eye did } \\
\text { not have SMD and was placed in the non-SMD sub-group. Three of the nine cases in } \\
\text { Group two had a history of biocular PRP and were designated as the PRP-treated sub- } \\
\text { group. The other six cases were placed in the non-PRP-treated sub-group. }\end{array}$ & EDI-OCT \\
\hline Kim et al. & $\begin{array}{l}\text { Seoul, } \\
\text { Republic } \\
\text { of Korea }\end{array}$ & $\begin{array}{l}\text { December } \\
2016-\text { April } \\
2017\end{array}$ & $\begin{array}{l}\text { The study included } 185 \text { eyes of patients with a confirmed diagnosis of type two DM and } 45 \\
\text { eyes of healthy controls. }\end{array}$ & SS-OCT \\
\hline $\begin{array}{l}\text { Sudhalkar et } \\
\text { al. [22] }\end{array}$ & India & $\begin{array}{l}\text { September } \\
\text { 2012-July } \\
2013\end{array}$ & $\begin{array}{l}\text { The study group had } 227 \text { eyes of } 125 \text { subjects with type two DM. Out of } 227 \text { eyes, } 74 \text { eyes } \\
\text { did not have any evidence of DR, } 89 \text { eyes of NPDR, } 33 \text { eyes had treatment naïve PDR, and } \\
31 \text { eyes with PRP treated PDR. The control group eventually consisted of } 197 \text { eyes of } 110 \\
\text { healthy subjects. }\end{array}$ & EDI-OCT \\
\hline $\begin{array}{l}\text { Totan et al. } \\
\text { [23] }\end{array}$ & Turkey & $\begin{array}{l}\text { December } \\
\text { 2013- } \\
\text { August } \\
2014\end{array}$ & $\begin{array}{l}\text { A total of } 34 \text { patients who had type two DM with treatment naïve DME and } 34 \text { sex-matched } \\
\text { healthy subjects were included. Only one eye from each subject was included for analysis. } \\
\text { If both eyes qualified, the eye with worse BCVA was selected. }\end{array}$ & $\begin{array}{l}\text { Cirrus HD- } \\
\text { OCT }\end{array}$ \\
\hline $\begin{array}{l}\text { Gerendas et } \\
\text { al. [24] }\end{array}$ & $\begin{array}{l}\text { Vienna, } \\
\text { Austria }\end{array}$ & 2013 & $\begin{array}{l}284 \text { treatment-naïve eyes of } 142 \text { patients with CSME and } 20 \text { controls. } 27 \text { patients }(19 \%) \\
\text { were excluded. Accordingly, data from } 115 \text { patients }(81 \%) \text { were processed by an } \\
\text { automated analysis. }\end{array}$ & SD-OCT \\
\hline et al. & & October & 203 eyes of 203 diabetic participants and 48 eyes of 48 healthy controls. The study & \\
\hline
\end{tabular}




\section{Cureus}

\begin{tabular}{|c|c|c|c|c|}
\hline [25] & Korea & $\begin{array}{l}\text { 2011-June } \\
2012\end{array}$ & $\begin{array}{l}\text { population included } 59 \text { eyes with no diabetic change, } 56 \text { eyes with mmNPDR, } 40 \text { eyes with } \\
\text { severe NPDR, and } 48 \text { eyes with PDR. Only naive eyes of various DR grades were included. }\end{array}$ & EDI-OCT \\
\hline $\begin{array}{l}\text { Adhi et al. } \\
\text { [26] }\end{array}$ & USA & $\begin{array}{l}\text { February } \\
1,2010- \\
\text { June } 30 \\
2012\end{array}$ & $\begin{array}{l}33 \text { eyes of } 33 \text { patients with DR and } 24 \text { eyes of } 24 \text { controls. Patients were classified into } \\
\text { NPDR without ME (nine eyes), PDR without ME ( } 10 \text { eyes), and DME (14 eyes). }\end{array}$ & SD-OCT \\
\hline $\begin{array}{l}\text { Regatieri et } \\
\text { al. [27] }\end{array}$ & USA & $\begin{array}{l}\text { December } \\
\text { 2009-June } \\
2010\end{array}$ & $\begin{array}{l}49 \text { eyes of } 49 \text { type two DM patients and } 24 \text { eyes of } 24 \text { normal patients. The patients with } \\
\text { DM were classified into three groups, } 11 \text { patients ( } 11 \text { eyes) with mmNPDR and no ME } \\
\text { (NPDR group), } 18 \text { patients (18 eyes) with mmNPDR and DME (DME group), and } 20 \text { patients } \\
\text { (20 eyes) with treated PDR and no DME (treated PDR group). }\end{array}$ & $\begin{array}{l}\text { Cirrus HD- } \\
\text { OCT }\end{array}$ \\
\hline $\begin{array}{l}\text { Gołębiewska } \\
\text { et al. [28] }\end{array}$ & Poland & 2017 & $\begin{array}{l}64 \text { right eyes of } 64 \text { subjects with type one DM and } 45 \text { right eyes of } 45 \text { age-matched } \\
\text { healthy volunteers (control group) were enrolled in this study. The mean age of the } \\
\text { subjects and controls was } 15.3 \text { and } 14.6 \text {, respectively. }\end{array}$ & SD-OCT \\
\hline $\begin{array}{l}\text { Kim et al. } \\
\text { [29] }\end{array}$ & $\begin{array}{l}\text { Seoul, } \\
\text { Republic } \\
\text { of Korea }\end{array}$ & $\begin{array}{l}\text { December } \\
\text { 2016- } \\
\text { December } \\
2017\end{array}$ & $\begin{array}{l}\text { A total of } 174 \text { eyes (132 eyes of } 81 \text { patients with type two DM and } 42 \text { eyes of } 28 \text { healthy } \\
\text { controls). We divided eyes into six groups: healthy controls ( } n=42) \text {, no } D R \text { ( } n=30 \text { ), mild } \\
\text { NPDR ( } n=22) \text {, moderate NPDR ( } n=23 \text { ), severe NPDR ( } n=42) \text {, and PDR ( } n=15) \text {. }\end{array}$ & $\begin{array}{l}\text { SS-OCT } \\
\text { and OCTA }\end{array}$ \\
\hline $\begin{array}{l}\text { Dodo et al. } \\
\text { [30] }\end{array}$ & Japan & $\begin{array}{l}\text { February } \\
2015- \\
\text { August } \\
2016\end{array}$ & 108 eyes of 66 consecutive patients with DM were evaluated. & OCTA \\
\hline $\begin{array}{l}\text { Nesper et al. } \\
\text { [31] }\end{array}$ & $\begin{array}{l}\text { Chicago, } \\
\text { Illinois, } \\
\text { USA }\end{array}$ & $\begin{array}{l}\text { June } \\
2015-J u l y \\
2016\end{array}$ & $\begin{array}{l}137 \text { eyes of } 86 \text { patients with different stages of DR and } 44 \text { eyes of } 26 \text { healthy age-matched } \\
\text { controls. }\end{array}$ & OCTA \\
\hline
\end{tabular}

\section{TABLE 1: General descriptive details of the studies from the review.}

BCVA: best corrected visual acuity, CSME: clinically significant macular edema, DM: diabetes mellitus, DME: diabetic macular edema, DR: diabetic retinopathy, EDI-OCT: enhanced depth imaging optical coherence tomography, HD-OCT: high-definition optical coherence tomography, ME: macular edema, mmNPDR: mild-to-moderate non-proliferative diabetic retinopathy, msNPDR: moderate-to-severe non-proliferative diabetic retinopathy, NPDR: non-proliferative diabetic retinopathy, OCTA: optical coherence tomography angiography, PDR: proliferative diabetic retinopathy, PRP: pan-retinal photocoagulation, SMD: serous macular detachment, SS-OCT: swept-source optical coherence tomography.

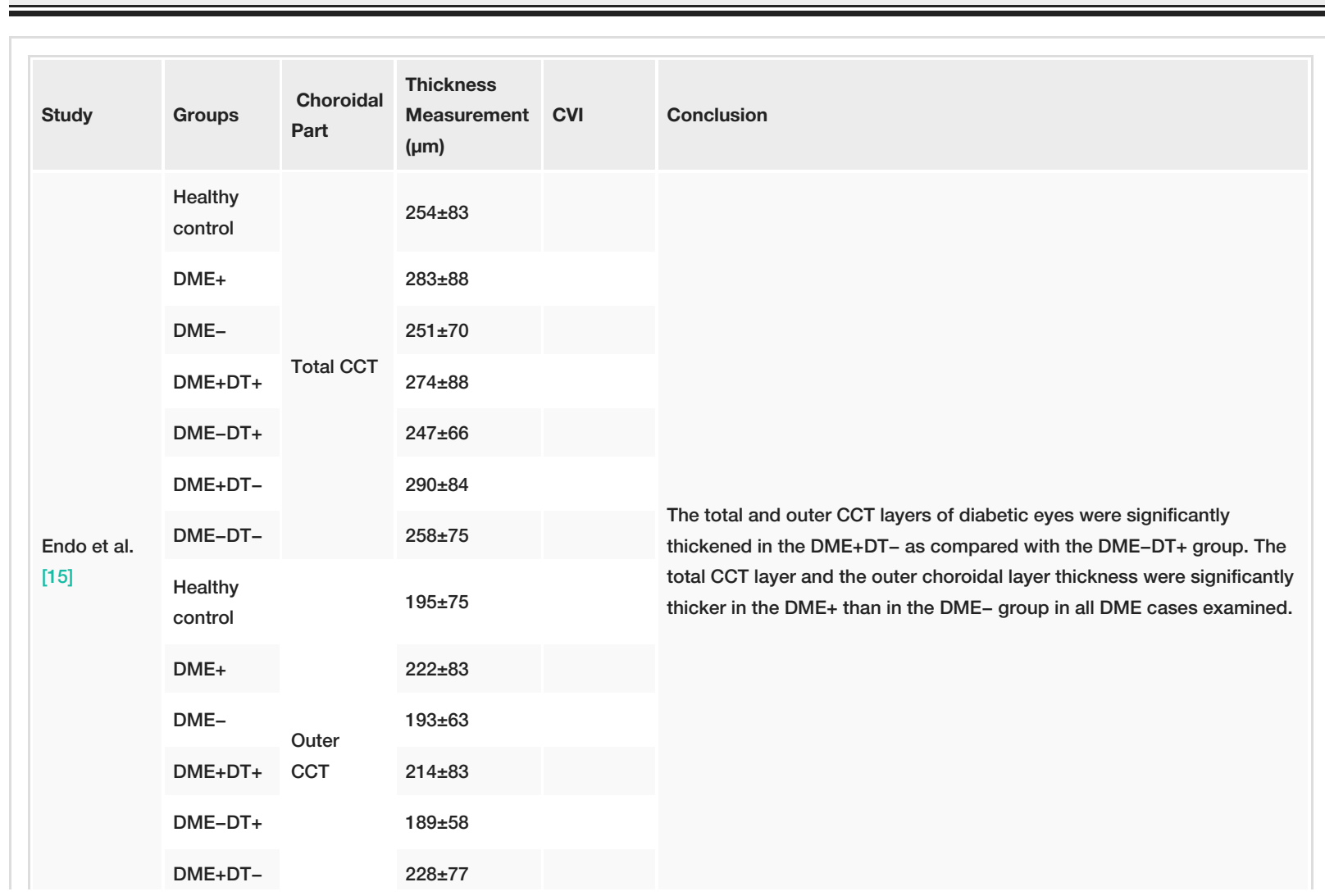




\section{Cureus}

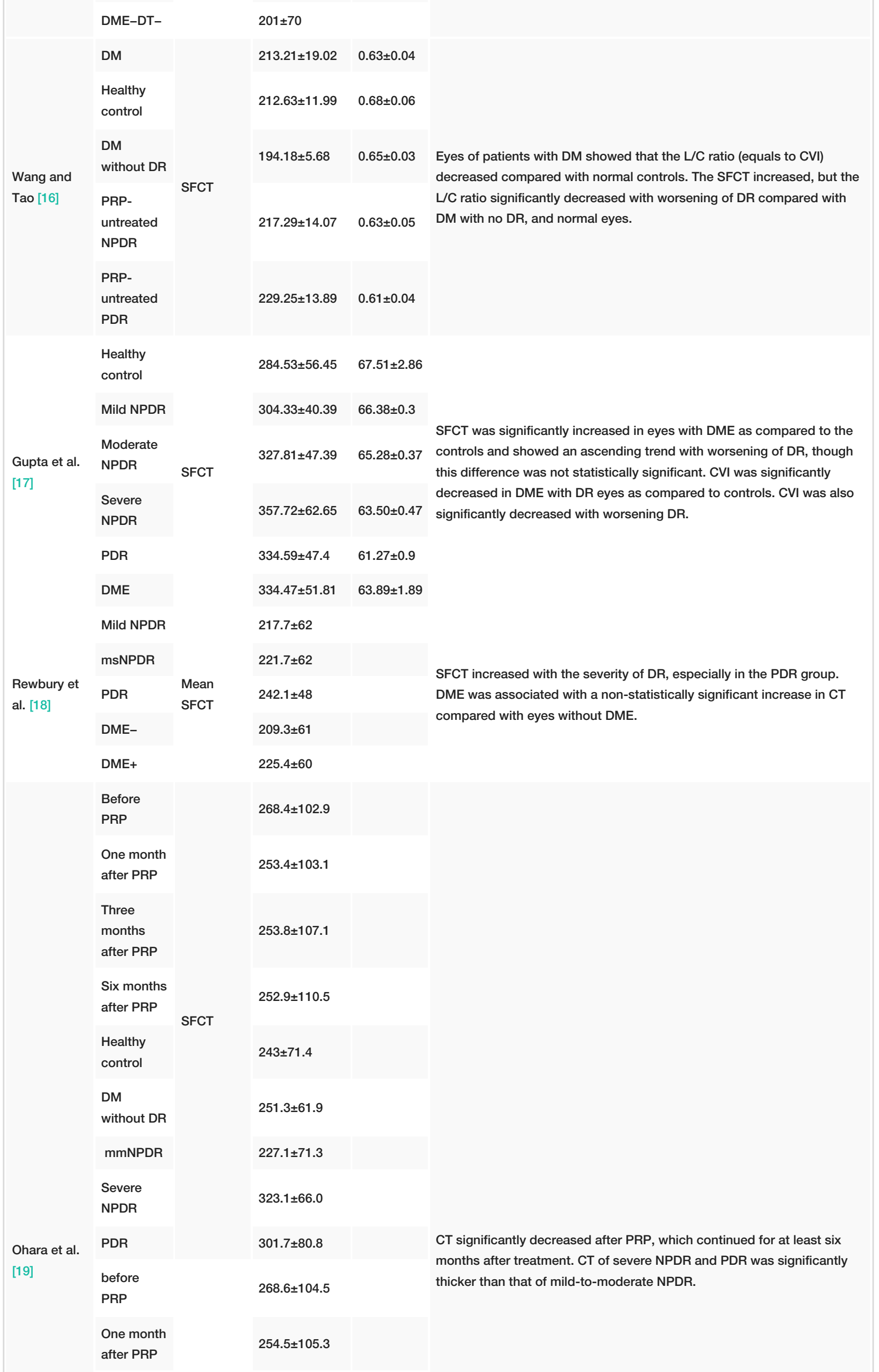




\section{Cureus}

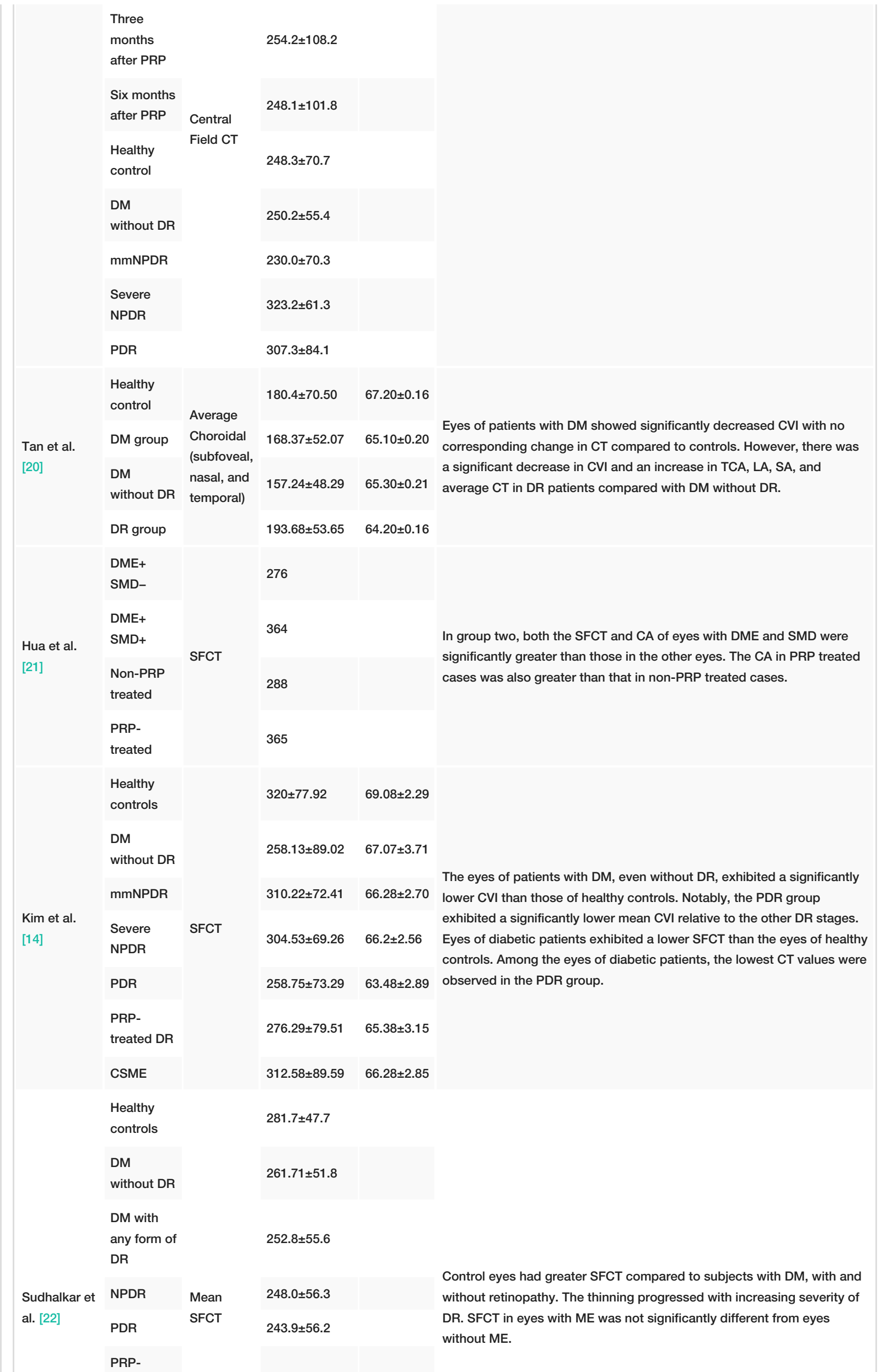




\section{Cureus}

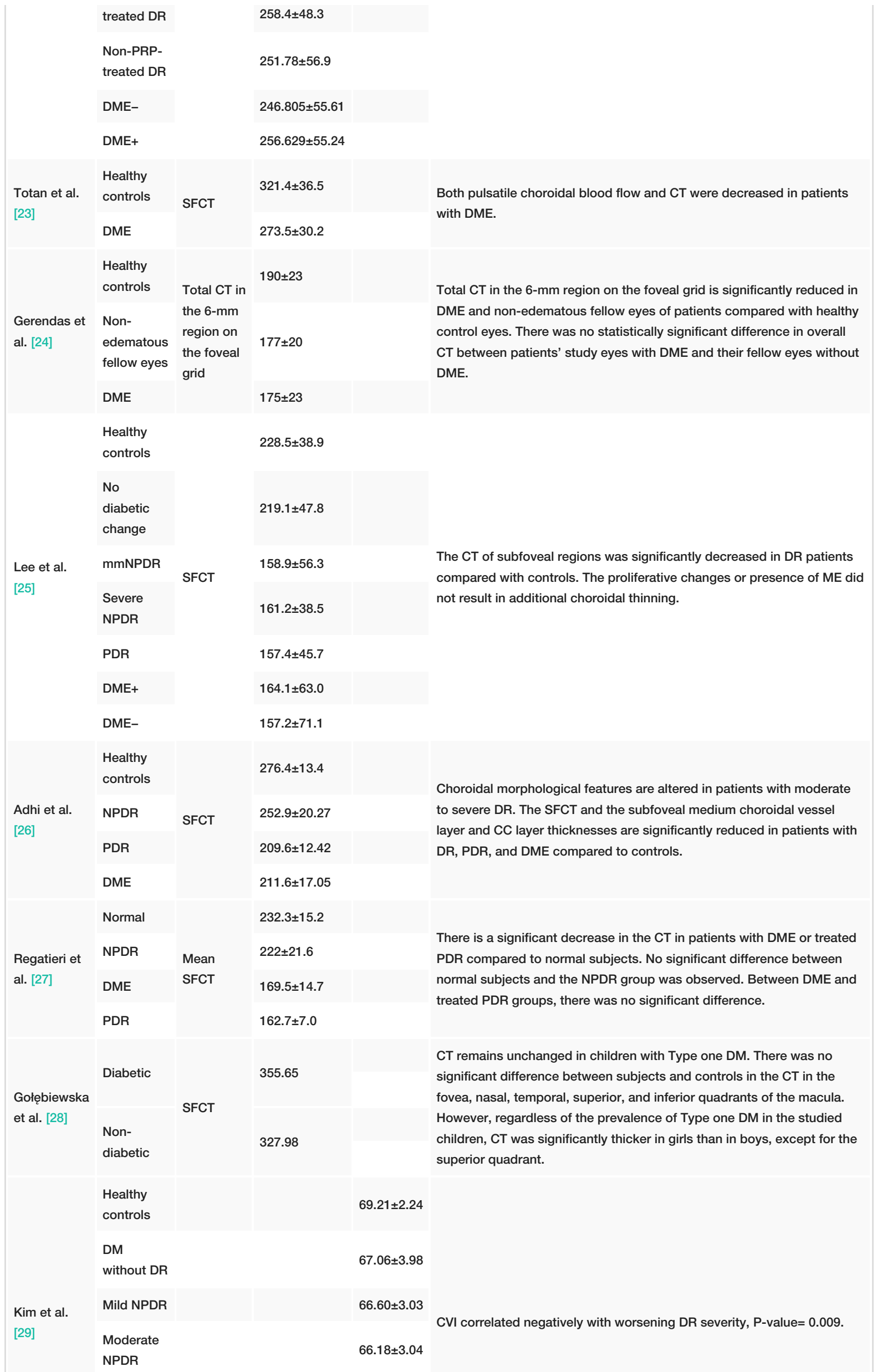




\section{Cureus}

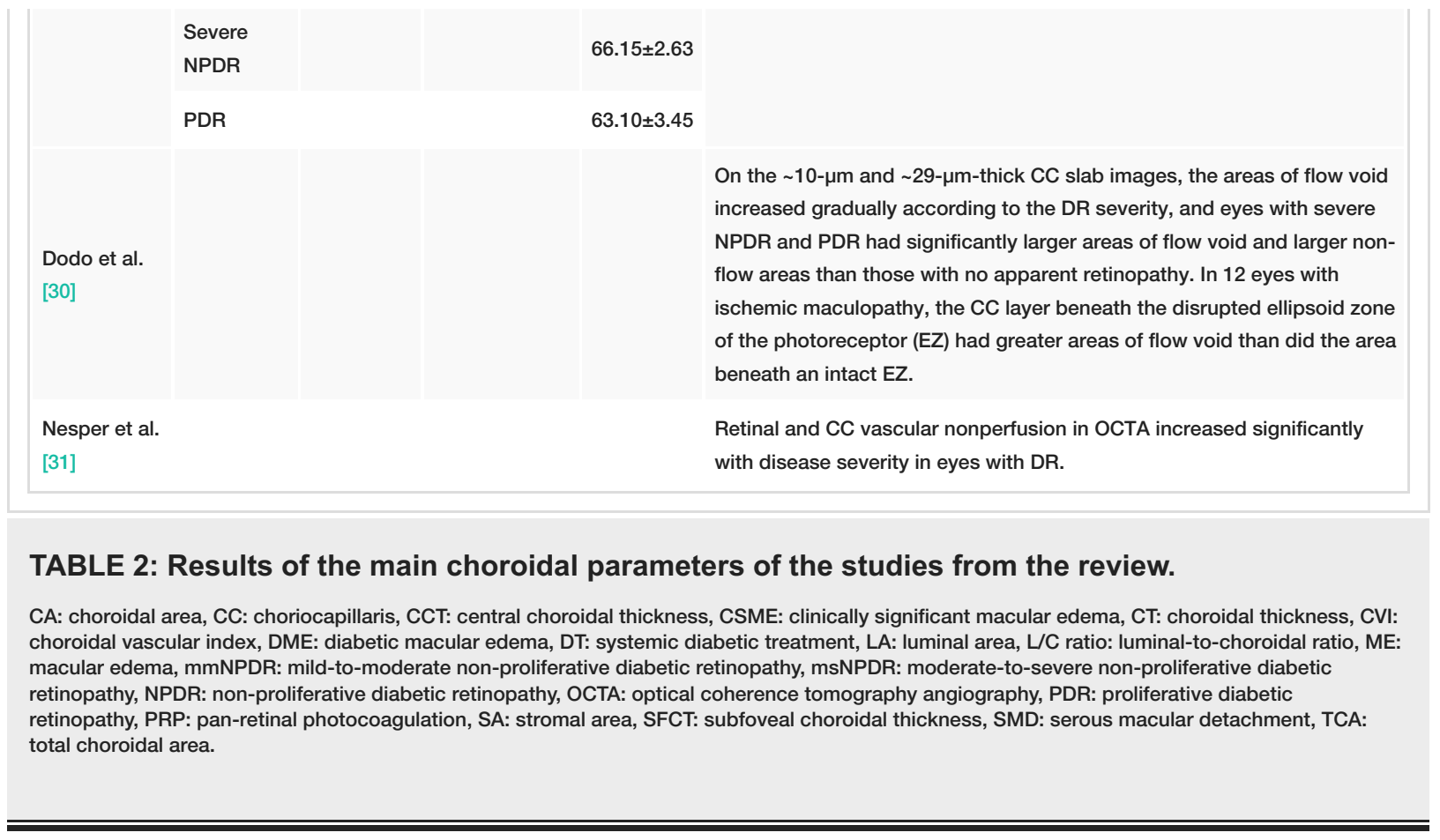

In Wang and Tao, for TCA and SA, the pairwise comparisons showed $0.81 \pm 0.06 \mathrm{~mm}^{2} ; 0.28 \pm 0.03 \mathrm{~mm}^{2}$, $0.86 \pm 0.09 \mathrm{~mm}^{2} ; 0.31 \pm 0.05 \mathrm{~mm}^{2}, 0.90 \pm 0.08 \mathrm{~mm}^{2} ; 0.34 \pm 0.03 \mathrm{~mm}^{2}$ for DM without DR eyes, pan-retinal photocoagulation (PRP)-untreated NPDR eyes, and PRP-untreated PDR eyes, respectively [16].

In Tan et al., TCA, LA, and SA values were $0.81 \pm 0.25 \mathrm{~mm}^{2}, 0.54 \pm 0.16 \mathrm{~mm}^{2}$, and $0.27 \pm 0.09 \mathrm{~mm}^{2}$ in controls and $0.83 \pm 0.28 \mathrm{~mm}^{2}, 0.54 \pm 0.18 \mathrm{~mm}^{2}$, and $0.29 \pm 0.10 \mathrm{~mm}^{2}$ in DM group. The same values were $0.75 \pm 0.28 \mathrm{~mm}^{2}$, $0.49 \pm 0.18 \mathrm{~mm}^{2}$, and $0.26 \pm 0.10 \mathrm{~mm}^{2}$ in DM with no DR and $0.97 \pm 0.24 \mathrm{~mm}^{2}, 0.62 \pm 0.15 \mathrm{~mm}^{2}$, and $0.34 \pm 0.09$ $\mathrm{mm}^{2}$ in DR group [20].

In Hua et al., in group two (DME group), choroidal area (CA) was $906.246 \mu \mathrm{m}^{2}, 798,066 \mu \mathrm{m}^{2}, 947,448 \mu \mathrm{m}^{2}$, and $777,474 \mu \mathrm{m}^{2}$ in eyes with DME and serous macular detachment (SMD), eyes with DME without SMD, PRP treated, and non-PRP treated cases, respectively [21].

Totan et al. concluded that the mean ocular pulse amplitude (OPA) values were $2.58 \pm 0.96,3.52 \pm 1.03$ in patients with DME and controls, respectively [23].

In Adhi et al., large vessel choroidal layer thickness was $224.0 \pm 13.5 \mu \mathrm{m}, 206.6 \pm 18.01 \mu \mathrm{m}, 169.2 \pm 12.43 \mu \mathrm{m}$, and $173.7 \pm 14.63 \mu \mathrm{m}$ in healthy eyes, NPDR, PDR, and DME eyes, respectively. Medium choroidal vessel layer and choriocapillaris (CC) layer thickness was $52.5 \pm 1.8 \mu \mathrm{m}, 46.3 \pm 3.6 \mu \mathrm{m}, 40.4 \pm 2.96 \mu \mathrm{m}$, and $37.93 \pm 3.3$ $\mu \mathrm{m}$ in the same groups, respectively [26].

In Gołębiewska et al., CT in the fovea, nasal, temporal, superior, and inferior quadrants of the macula was $355.65 \mu \mathrm{m}, 282.32 \mu \mathrm{m}, 338.88 \mu \mathrm{m}, 342.40 \mu \mathrm{m}$, and $352.35 \mu \mathrm{m}$ in diabetic and $327.98 \mu \mathrm{m}, 267.16 \mu \mathrm{m}, 324.07$ $\mu \mathrm{m}, 328.70 \mu \mathrm{m}$, and $354.56 \mu \mathrm{m}$ in the non-diabetic group, respectively [28].

Dodo et al. found that on the $\sim 10-\mu \mathrm{m}$ and $\sim 29-\mu \mathrm{m}$-thick CC slab images, according to the DR severity, the areas of flow void increased gradually. In 12 eyes with ischemic maculopathy, the CC layer beneath the intact ellipsoid zone of the photoreceptor (EZ) and beneath the disrupted EZ had area of flow void as $2.00 \pm 1.10 \%, 6.28 \pm 3.34 \%$, respectively [30].

In Nesper et al., the percent area of nonperfusion (PAN) measured in the CC was $2.53 \pm 0.69 \%, 3.39 \pm 1.37 \%$, $3.37 \pm 1.08 \%$, and $4.40 \pm 1.68 \%$ in healthy controls, DM without DR, NPDR, and PDR, respectively. The mean adjusted flow index (AFI) in the CC was $0.393 \pm 0.020,0.392 \pm 0.022,0.382 \pm 0.026$, and $0.380 \pm 0.027$ in the same groups, respectively [31].

\section{Limitations}

1. Several studies did not adjust for physiologic, systemic, and local ocular variables that can be considered as confounders and affect the results of CT. These factors include blood pressure, age, axial length, refractive error, anterior chamber depth, diurnal variation, race, duration of DM, different kinds of DM medications, 
exposure to PRP, intravitreal anti-VEGF, and steroids.

2. Several studies also had small sample sizes, which can reduce the strength of statistical analysis and affect the results.

3. Only free full-text articles available on the PubMed database were used.

\section{Discussion}

Studies Showing Increasing CT in DM Patients or With Worsening DR

Endo et al. found that the total central choroidal thickness (CCT) layer in the DME positive (DME+) was significantly thicker than the DME negative (DME-) group $(\mathrm{P}<0.05)$. The outer CCT layer in DME+ was significantly thicker than the DME- group $(\mathrm{P}<0.05)$. The total and outer CCT layer in DME+ without systemic diabetic treatment (DME+DT-) was significantly thicker than the DME- with systemic diabetic treatment $(\mathrm{DME}-\mathrm{DT}+)$ group $(\mathrm{P}<0.05)$. In contrast, between the groups, there was no significant difference in the inner choroidal layer. In stage of DR, the inner CCT layer was significantly thicker in severe NPDR compared to the control group $(\mathrm{P}<0.05)[15]$.

In Wang and Tao, the luminal-to-choroidal area (L/C ratio) values, which are equal to CVI, were significantly decreased in DM compared to the healthy group $(\mathrm{P}<0.001)$. But there were no statistically significant differences in SFCT between the two groups ( $\mathrm{P}=0.849)$. The SFCT values were significantly lower in DM without DR eyes, followed by PRP-untreated NPDR eyes and PRP-untreated PDR eyes. For TCA and SA, the pairwise comparisons showed that DM with no DR eyes were significantly lower compared with PRPuntreated NPDR eyes and PRP-untreated PDR eyes $(\mathrm{P}<0.001)$. Relative to the eyes of DM without DR, the $\mathrm{L} / \mathrm{C}$ ratio values for eyes of PRP-untreated NPDR and PRP-untreated PDR patients were significantly lower $(\mathrm{P}=0.019)[16]$.

Gupta et al. found that SFCT significantly increased in eyes with DME as compared to controls $(\mathrm{P}<0.001)$ and showed an increasing thickness with worsening of DR, although this difference was not statistically significant $(\mathrm{P}=0.09)$. CVI was significantly decreased in DME with DR eyes as compared to controls $(\mathrm{P}<0.001)$. CVI was also significantly decreased with worsening $\mathrm{DR}(\mathrm{P}<0.001)$. Patients with hypertension were significantly found to have thinner SFCT when compared with non-hypertensive patients $(319.0 \pm 54.6 \mu \mathrm{m}$ vs. $354.0 \pm 48.8 \mu \mathrm{m}(\mathrm{P}=0.01))$. The presence of hypertension did not affect CVI [17].

In Rewbury et al., there was a statistically significant increase in CT in PDR when compared with mild NPDR group $(\mathrm{P}=0.027)$. The increase in SFCT in the moderate-to-severe non-proliferative diabetic retinopathy (msNPDR) group compared with the mild NPDR group was not statistically significant $(\mathrm{P}=0.17)$. Compared with eyes without DME, DME was associated with a non-statistically significant increase in CT $(\mathrm{P}=0.13)[18]$.

In Ohara et al., the central field CT was significantly decreased at one, three, and six months after PRP $(\mathrm{P}<0.0001)$. SFCT was significantly decreased at one, three, and six months after treatment $(\mathrm{P}=0.0002)$. The central field CT of severe NPDR was significantly thicker than that of normal and mild-to-moderate nonproliferative diabetic retinopathy ( $\mathrm{mmNPDR}$ ) ( $\mathrm{P}=0.0455$ and 0.0099 , respectively). Moreover, the central field CT of PDR was significantly thicker than mmNPDR $(\mathrm{P}=0.0169)$. In addition, SFCT of the PDR group was significantly thicker than that of mmNPDR group; SFCT of severe NPDR group was significantly thicker than that of normal and mmNPDR groups. The results of SFCT and central field CT were extremely similar [19].

In Tan et al., the results showed that there were no significant differences between patients with DM and controls in TCA $(\mathrm{P}=0.78)$, LA $(\mathrm{P}=0.90)$, SA $(\mathrm{P}=0.33)$, and average CT $(\mathrm{P}=0.40)$. However, there was a significantly lower CVI in patients with $\mathrm{DM}$ as compared to controls $(\mathrm{P}<0.0001)$. However, the results showed a significant increase in TCA $(\mathrm{P}=0.026)$, LA $(\mathrm{P}=0.036)$, SA $(\mathrm{P}=0.01)$, and average CT $(\mathrm{P}=0.05)$ in DR patients compared with DM without DR. Moreover, there was a significantly lower CVI in patients with DR as compared to DM without DR $(\mathrm{P}=0.035)[20]$.

In Hua et al., in group one (DR cases), choroidal abnormalities that were evident using ICGA but not fundus fluorescein angiography (FFA) included early hypo-fluorescent spots, late hyperfluorescent spots, and late choroidal nonperfusion regions in $75.81 \%, 59.68 \%$, and $51.61 \%$ of the DR eyes, respectively. In particular, a significant difference between PDR in 17 of 23 eyes (73.91\%) and non-PDR in 16 of 39 eyes (41.03\%) was observed in late choroidal non-perfusion regions. In group two (DME group), both the SFCT and choroidal area (CA) of eyes with DME and serous macular detachment (SMD) were significantly greater than those in the other eyes. The CA in PRP treated cases was also greater than that in non-PRP treated cases [21].

The previous studies showed an increase in CT as DR worsens. This can be explained by the increased secretion of intraocular VEGF. DM is known to cause microvascular abnormalities, which can lead to ischemia and hypoxia in the choroidal vasculature and adjacent retinal tissue, which in turn leads to increased secretion of VEGF, a known cytokine that mediates vascular hyper-permeability and fluid leakage leading to increased CT. However, in many studies, we found that CT decreases in DM patients with 
no retinopathy and during the early stages of DR. This can be explained by decreasing capillary perfusion and ischemia of the choroid in the early stages, leading to a decreased vascular layer of the choroid and CT. However, with the progression of DR, hypoxia leads to more VEGF secretion leading to neovascularization, vascular hyper-permeability, fluid leakage, increased blood flow, and increased CT. These findings suggest that changes in choroidal vasculature could be the primary event in the pathogenesis of DM, even without clinical evidence of DR.

Studies Showing Decreasing CT in DM Patients or With Worsening DR

Kim et al. concluded that the eyes of DM patients exhibited a significantly lower mean CVI $(\mathrm{P}<0.001)$ relative to healthy controls. Notably, the PDR group exhibited a significantly lower mean CVI relative to controls $(\mathrm{P}<0.001)$, DM group without $\mathrm{DR}(\mathrm{P}=0.029)$, and mmNPDR group $(\mathrm{P}=0.015)$. In comparison with other DR groups, no significant change in CVI was observed in the clinically significant macular edema (CSME) group. Eyes of DM patients exhibited a lower SFCT than the eyes of healthy controls. The lowest CT values among the eyes of DM patients were observed in the PDR group. In the DM group without DR, SFCT decreased significantly than mmNPD group and severe NPDR group $(\mathrm{P}=0.009$ and $\mathrm{P}=0.018$, respectively) [14].

In Sudhalkar et al., a statistically significant subfoveal choroidal thinning was observed in eyes with DR when compared to subjects with DM without DR $(\mathrm{P}<0.001)$ and age-matched healthy eyes $(\mathrm{P}<0.011)$. There was no significant difference in SFCT between eyes with DR, who had undergone PRP and eyes that had not undergone PRP ( $\mathrm{P}=0.23)$. SFCT decreased with increasing severity of $\mathrm{DR}$. As compared to those with NPDR, patients with PDR had statistically significantly thinner subfoveal choroids $(\mathrm{P}=0.021)$. In eyes with macular edema (ME), the mean SFCT was not significantly different from eyes without $\mathrm{ME}(\mathrm{P}=0.196)$ [22].

In Totan et al., mean OPA values in patients with DME were statistically decreased compared with controls $(\mathrm{P}<0.001)$. Mean SFCT, nasal and temporal CT values were significantly decreased in DME eyes compared to controls $(\mathrm{P}<0.001)[23]$.

In Gerendas et al., total CT in the 6-mm region on the foveal grid is significantly reduced in DME $(\mathrm{P}=0.0016)$ and non-edematous fellow eyes $(\mathrm{P}=0.009)$ of patients compared with healthy controls. Overall, CT between patients' study eyes with DME and their fellow eyes without DME had no statistically significant difference. Choroidal thinning in this study also equally affected fellow eyes without ME, suggesting a systemic pathophysiologic mechanism unrelated to the presence of retinal disease [24].

In Lee et al., SFCT was thickest among the controls. Between the no diabetic change group and the controls, there was no significant difference $(\mathrm{P}=0.846)$; however, a significant decrease in CT was observed in mmNPDR, severe NPDR, and PDR groups $(\mathrm{P}=0.005, \mathrm{P}<0.001$, and $\mathrm{P}<0.001$, respectively) compared with controls. There were no significant differences among mmNPDR, severe NPDR, and PDR groups $(\mathrm{P}>0.05)$. Eyes exhibiting ME had no significant difference in CT compared with eyes having normal macular contours [25].

In Adhi et al., the choroidoscleral interface had an irregular contour in eight of nine eyes with NPDR (89\%), nine of 10 eyes with PDR (90\%), and 13 of 14 eyes with DME (93\%) compared with 0 of 24 controls. Mean SFCT and mean combined subfoveal medium choroidal vessel layer and CC layer thickness were significantly reduced in eyes with DR compared with controls. The same significant reduction was seen in PDR and DME groups compared to controls $(\mathrm{P}<0.05)$. The maximum CT was subfoveal in $22 \%$ of eyes with NPDR, $20 \%$ of eyes with PDR, and $14 \%$ of eyes with DME compared with $96 \%$ of eyes in controls. Focal thinning of the choroid with respect to the mean CT measurements at the corresponding locations in healthy eyes was observed in $0 \%, 56 \%, 40 \%$, and $86 \%$ of eyes in controls, NPDR, PDR, and DME groups, respectively [26].

In Regatieri et al., there was a statistically significant decrease in CT of DME and treated PDR group compared to normal subjects $(\mathrm{P}<0.001)$. No significant difference was observed between normal subjects vs. NPDR group, and DME vs. treated PDR groups $(\mathrm{P}>0.05)[27]$.

In the previous section, choroidal thinning associated with DR progression might be explained by CC loss or vascular constriction secondary to choroidal hypoxia leading to decreased CT.

Studies Showing No Change in CT in DM Patients or With Worsening DR

In Gołębiewska et al., CT in the fovea, nasal, temporal, superior, and inferior quadrants of the macula did not differ statistically between the study groups: $\mathrm{P}=0.134, \mathrm{P}=0.270, \mathrm{P}=0.691, \mathrm{P}=0.504$, and $\mathrm{P}=0.862$, respectively. There were no significant correlations between CT vs. hemoglobin A1C (HbA1C) level and duration of diabetes ( $\mathrm{P}=0.197$ and $\mathrm{P}=0.272$, respectively). However, the $\mathrm{CT}$ was significantly thicker in girls than in boys, except for the superior quadrant, regardless of the prevalence of type one DM in the studied children. This difference could be due to different hormonal exposure between males and females because estrogens and progestins can have vascular effects that can affect choroidal blood flow [28]. 
In the previous three sections, we saw a discrepancy (increased, decreased, no change) in CT in diabetic patients with and without DR compared to healthy controls. This discrepancy can be explained by the following points. First, many studies investigated only the central choroid, and the parafoveal CT may show different results among the same studies. Second, many studies ignored considering systemic treatment for DM, and the different medications used in cases can affect CT differently. Third, many studies did not consider systemic confounding factors such as blood pressure, serum lipids, which are supposed to be higher in DM patients, which could affect the CT; for example, in Gupta et al., patients with hypertension were found to have significantly thinner SFCT when compared with non-hypertensive patients [16]. Fourth, CT measurement is different in some studies, which can affect the results obtained. Fifth, physiologic variables such as age, refractive errors, diurnal variation, axial length, races, sex, anterior chamber depth, duration of DM, smoking, and HbA1C can affect CT measurements, which were not adjusted for in many studies. Sixth, some studies have a small sample size, which decreases the statistical strength of the

analysis. Seventh, different classification of DR subgroups and the inclusion of patients with type one DM in some studies can affect CT differently than in type two DM. Eighth, many studies did not include treatment naïve eyes which were treated by PRP or intravitreal anti-VEGF or steroids, which can affect CT. Moreover, the time of measuring CT after PRP or ocular injection therapy can affect CT differently. Based on these factors, we can say that CT is not a robust tool for assessing DR progression because it can be affected by many physiologic, systemic, and local factors. Moreover, CT doesn’t tell us about which part of the choroid is affected at the microscopic level (stroma, vascular layer, or fluid).

Studies Investigating Other Choroidal Parameters but Not CT in DM Patients With and Without DR

Kim et al. found that CVI negatively correlated with worsening DR severity $(\mathrm{P}=0.009)$ [29].

In Dodo et al., on the $\sim 10-\mu$ m-thick CC slab images, according to the DR severity, the areas of flow void increased gradually, and eyes with moderate NPDR, severe NPDR, and PDR had significantly larger areas of flow void than those with no apparent retinopathy ( $\mathrm{P}=0.032, \mathrm{P}=0.009$, and $\mathrm{P}=0.002$, respectively). On the $\sim 29-\mu \mathrm{m}$-thick CC slab images, eyes with severe NPDR and PDR had greater areas of flow void than those with no apparent retinopathy. Eyes with severe NPDR and PDR had larger non-flow areas than those with no apparent retinopathy. In 12 eyes with ischemic maculopathy, the CC layer beneath the intact ellipsoid zone of the photoreceptor (EZ) had significantly smaller areas of flow void than did the area beneath the disrupted EZ $(\mathrm{P}<0.001)[30]$.

Nesper et al. concluded that the percent area of nonperfusion (PAN) measured in the CC increased significantly with increasing severity of DR $(\mathrm{P}<0.01)$. The mean adjusted flow index $(\mathrm{AFI})$ in the CC was correlated significantly negatively with DR severity $(\mathrm{P}<0.01)[31]$.

The results of this section confirm that choroidal vascular abnormalities are evident in DM patients and increase with worsening DR suggesting that choroidal vascular abnormalities might be an underlying pathologic process leading to DR.

\section{CT in DME Patients}

In this review, we found a discrepancy in CT measurements in DME patients in different studies (increased vs. decreased). Possible reasons for these different results include different inclusion criteria for DME patients, especially regarding different stages of DR in these patients. It's expected that if DME patients have a more severe stage of DR, such as PDR, they are highly expected to have different CT than those in earlier stages of DR. Moreover, systemic treatment or different medications used for treating DM could have an impact on CT in these patients. VEGF is an important cytokine that mediates vascular hyperpermeability, so an increase in VEGF levels, which is expected in an advanced stage of DR and DME, can affect CT in these patients. So it is important to consider if PRP, intravitreal anti-VEGF, and steroid injection have been used or not because they can have a significant impact on CT in these patients by reducing VEGF levels and possibly decreasing CT. Moreover, the time of measuring CT after these therapies can also affect the results. For example, it is expected that early after laser therapy, CT increases due to effusion of the choroid as a result of blood vessel injuries and due to shifting of blood flow to the central choroidal area after peripheral retinal exposure to thermal injury. All the samples investigated in the previous studies should be adjusted for these factors to have a better understanding of CT in DME patients.

For those studies with no significant change or decreasing CT in DME, this could be explained by CT being more affected by DR. For those studies with increasing CT in DME, this could be due to increased VEGF with a resultant increase in neovascularization, vascular hyperpermeability, fluid leakage and blood flow leading to increased CT.

\section{CVI in Diabetic Patients With and Without DR or ME}

In Gupta et al., we found that hypertensive patients had thinner choroid compared to non-hypertensive patients in the diabetic group. However, CVI was not affected by hypertension [17]. Moreover, in almost all studies mentioned in this article that investigated CVI, there was a significant decrease in CVI with 
worsening DR. This consensus reflects the stability of CVI compared with CT and makes it a more robust tool in assessing DR progression and the severity of the underlying disease. CVI may represent choroidal vascular changes, which can be a valuable tool even in DM patients with no apparent DR. However, CT can reflect secondary changes of edema and leakage that can be seen due to increased VEGF secretion. Because CVI is a ratio, it is less likely to be affected by the factors affecting CT, making it a better tool to be used in the evaluation of choroidopathy.

\section{Recommendations}

1. In future studies, inclusion of a larger sample size is required to confirm the results.

2. It is really important to adjust the study population for the factors that can affect CT to better understand the relationship between CT and the worsening of DR.

3. Using tools or variables that are less affected by systemic and physiologic factors, such as CVI, could be more beneficial in assessing the prognosis and progression of DR.

\section{Conclusions}

The choroid has an important contribution to the blood supply of the retina; therefore, assessment of different variables of the choroid can help in the evaluation and assessment of DR progression, which helps in the early diagnosis and treatment. The discrepancy seen in the results of various studies shows that CT does not correlate well with worsening DR or DME (can be increased or decreased) and can't be relied upon to assess the progression and severity of DR. This discrepancy is most likely because CT can be affected by various physiologic, systemic and local factors such as blood pressure, age, axial length, refractive error, anterior chamber depth, diurnal variation, race, sex, duration of DM, different kinds of DM treatments, exposure to PRP and intravitreal anti-VEGF or steroids. Some studies also have small sample sizes, which can reduce the strength of statistical analysis and affect the results.

CVI decreased significantly with worsening DR in almost all the studies which investigated it. CVI, which is defined as the proportion of LA to TCA, is considered a more robust marker for choroidal vascularity assessment and indirectly measures choroidal vascularity quantitatively, which enables us to overcome the limitation of using CT alone and makes it less affected by physiological factors. We postulate that CVI can be used to assess the progression of DR more accurately than CT. The results of this article affirm that choroidal vascular anomalies are apparent in DM patients and increment with worsening DR suggesting that choroidal vascular abnormalities may be a fundamental pathologic process driving to DR.

\section{Additional Information}

\section{Disclosures}

Conflicts of interest: In compliance with the ICMJE uniform disclosure form, all authors declare the following: Payment/services info: All authors have declared that no financial support was received from any organization for the submitted work. Financial relationships: All authors have declared that they have no financial relationships at present or within the previous three years with any organizations that might have an interest in the submitted work. Other relationships: All authors have declared that there are no other relationships or activities that could appear to have influenced the submitted work.

\section{References}

1. 2019-2020 Basic and Clinical Science Course, Section 12: Retina and Vitreous. McCannel CA, Berrocal AM, Holder G, Kim SJ, Leonard BC, Rosen RB, Spaide RF, Sun JK (ed): American Academy of Ophthalmology, San Francisco, United States; 2019.

2. Mrejen S, Spaide RF: Optical coherence tomography: imaging of the choroid and beyond . Surv Ophthalmol. 2013, 58:387-429. 10.1016/j.survophthal.2012.12.001

3. Hidayat AA, Fine BS: Diabetic choroidopathy. Light and electron microscopic observations of seven cases . Ophthalmology. 1985, 92:512-522. 10.1016/S0161-6420(85)34013-7

4. Shiragami C, Shiraga F, Matsuo T, Tsuchida Y, Ohtsuki H: Risk factors for diabetic choroidopathy in patients with diabetic retinopathy. Graefes Arch Clin Exp Ophthalmol. 2002, 240:436-442. 10.1007/s00417-0020451-5

5. Esmaeelpour M, Povazay B, Hermann B, et al.: Three-dimensional 1060-nm OCT: choroidal thickness maps in normal subjects and improved posterior segment visualization in cataract patients. Invest Ophthalmol Vis Sci. 2010, 51:5260-5266. 10.1167/iovs.10-5196

6. Querques G, Lattanzio R, Querques L, et al.: Enhanced depth imaging optical coherence tomography in type 2 diabetes. Invest Ophthalmol Vis Sci. 2012, 53:6017-6024. 10.1167/iovs.12-9692

7. Rasheed MA, Goud A, Mohamed A, Vupparaboina KK, Chhablani J: Change in choroidal vascularity in acute central serous chorioretinopathy. Indian J Ophthalmol. 2018, 66:530-534. 10.4103/ijo.IJO_1160_17

8. $\mathrm{Xu} \mathrm{J}, \mathrm{Xu} \mathrm{L}, \mathrm{Du} \mathrm{KF}$, et al.: Subfoveal choroidal thickness in diabetes and diabetic retinopathy . Ophthalmology. 2013, 120:2023-2028. 10.1016/j.ophtha.2013.03.009

9. Nagaoka T, Kitaya N, Sugawara R, et al.: Alteration of choroidal circulation in the foveal region in patients with type 2 diabetes. Br J Ophthalmol. 2004, 88:1060-1063. 10.1136/bjo.2003.035345 
10. Schocket LS, Brucker AJ, Niknam RM, Grunwald JE, DuPont J, Brucker AJ: Foveolar choroidal hemodynamics in proliferative diabetic retinopathy. Int Ophthalmol. 2004, 25:89-94. 10.1023/b:inte.0000031744.93778.60

11. Spaide RF, Koizumi H, Pozzoni MC: Enhanced depth imaging spectral-domain optical coherence tomography. Am J Ophthalmol. 2008, 146:496-500. 10.1016/j.ajo.2008.05.032

12. Potsaid B, Baumann B, Huang D, et al.: Ultrahigh speed 1050nm swept source/Fourier domain OCT retinal and anterior segment imaging at 100,000 to 400,000 axial scans per second. Opt Express. 2010, 18:2002920048. 10.1364/OE.18.020029

13. Agrawal R, Gupta P, Tan KA, Cheung CMG, Wong TY, Cheng CY: Choroidal vascularity index as a measure of vascular status of the choroid: measurements in healthy eyes from a population-based study. Sci Rep. 2016, 6:21090. 10.1038/srep21090

14. Kim M, Ha MJ, Choi SY, Park YH: Choroidal vascularity index in type-2 diabetes analyzed by swept-source optical coherence tomography. Sci Rep. 2018, 8:70. 10.1038/s41598-017-18511-7

15. Endo H, Kase S, Takahashi M, et al.: Relationship between diabetic macular edema and choroidal layer thickness. PLoS One. 2020, 15:0226630. 10.1371/journal.pone.0226630

16. Wang H, Tao Y: Choroidal structural changes correlate with severity of diabetic retinopathy in diabetes mellitus. BMC Ophthalmol. 2019, 19:186. 10.1186/s12886-019-1189-8

17. Gupta C, Tan R, Mishra C, et al.: Choroidal structural analysis in eyes with diabetic retinopathy and diabetic macular edema-A novel OCT based imaging biomarker. PLoS One. 2018, 13:0207435. 10.1371/journal.pone.0207435

18. Rewbury R, Want A, Varughese R, Chong V: Subfoveal choroidal thickness in patients with diabetic retinopathy and diabetic macular oedema. Eye (Lond). 2016, 30:1568-1572. 10.1038/eye.2016.187

19. Ohara Z, Tabuchi H, Nakakura S, Yoshizumi Y, Sumino H, Maeda Y, Kiuchi Y: Changes in choroidal thickness in patients with diabetic retinopathy. Int Ophthalmol. 2018, 38:279-286. 10.1007/s10792-0170459-9

20. Tan KA, Laude A, Yip V, Loo E, Wong EP, Agrawal R: Choroidal vascularity index - a novel optical coherence tomography parameter for disease monitoring in diabetes mellitus. Acta Ophthalmol. 2016, 94:612-616. 10.1111/aos.13044

21. Hua R, Liu L, Wang X, Chen L: Imaging evidence of diabetic choroidopathy in vivo: angiographic pathoanatomy and choroidal-enhanced depth imaging. PLoS One. 2013, 8:83494. 10.1371/journal.pone.0083494

22. Sudhalkar A, Chhablani JK, Venkata A, Raman R, Rao PS, Jonnadula GB: Choroidal thickness in diabetic patients of Indian ethnicity. Indian J Ophthalmol. 2015, 63:912-916. 10.4103/0301-4738.176024

23. Totan Y, Akyüz TK, Güler E, Güragaç FB: Evaluation of ocular pulse amplitude and choroidal thickness in diabetic macular edema. Eye (Lond). 2016, 30:369-374. 10.1038/eye.2015.232

24. Gerendas BS, Waldstein SM, Simader C, et al.: Three-dimensional automated choroidal volume assessment on standard spectral-domain optical coherence tomography and correlation with the level of diabetic macular edema. Am J Ophthalmol. 2014, 158:1039-1048. 10.1016/j.ajo.2014.08.001

25. Lee HK, Lim JW, Shin MC: Comparison of choroidal thickness in patients with diabetes by spectral-domain optical coherence tomography. Korean J Ophthalmol. 2013, 27:433-439. 10.3341/kjo.2013.27.6.433

26. Adhi M, Brewer E, Waheed NK, Duker JS: Analysis of morphological features and vascular layers of choroid in diabetic retinopathy using spectral-domain optical coherence tomography. JAMA Ophthalmol. 2013, 131:1267-1274. 10.1001/jamaophthalmol.2013.4321

27. Regatieri CV, Branchini L, Carmody J, Fujimoto JG, Duker JS: Choroidal thickness in patients with diabetic retinopathy analyzed by spectral-domain optical coherence tomography. Retina. 2012, 32:563-568. 10.1097/IAE.0b013e31822f5678

28. Gołębiewska J, Olechowski A, Wysocka-Mincewicz M, et al.: Choroidal thickness and ganglion cell complex in pubescent children with type 1 diabetes without diabetic retinopathy analyzed by spectral domain optical coherence tomography. J Diabetes Res. 2018, 2018:5458015. 10.1155/2018/5458015

29. Kim M, Choi SY, Park YH: Quantitative analysis of retinal and choroidal microvascular changes in patients with diabetes. Sci Rep. 2018, 8:12146. 10.1038/s41598-018-30699-w

30. Dodo Y, Suzuma K, Ishihara K, et al.: Clinical relevance of reduced decorrelation signals in the diabetic inner choroid on optical coherence tomography angiography. Sci Rep. 2017, 7:5227. 10.1038/s41598-01705663-9

31. Nesper PL, Roberts PK, Onishi AC, Chai H, Liu L, Jampol LM, Fawzi AA: Quantifying microvascular abnormalities with increasing severity of diabetic retinopathy using optical coherence tomography angiography. Invest Ophthalmol Vis Sci. 2017, 58:307-315. 10.1167/iovs.17-21787 